\title{
Redes de Conexão Ubíqua e Educação Online: o que nos revela um mapeamento sistemático de literatura
}

\author{
Ubiquitous Connection Networks and Online Education: what a systematic \\ mapping of literature reveals
}

\author{
Cláudia Leyendecker, Bento Silva \\ Universidade do Minho
}

\begin{abstract}
Resumo
Vivemos em cenários de intensa ubiquidade, o que traz importantes desafios para a Educação Online. Buscando compreender melhor esse novo horizonte que desaponta, o presente trabalho realizou um mapeamento sistemático de literatura com o objetivo de refletir sobre o potencial das Redes de Conexão Ubíqua para a Educação Online. Em nossos achados observamos que as discussões em torno do potencial das Redes de Conexão Ubíquas para o contexto da Educação Online, ainda precisam avançar. Entretanto, há boas iniciativas de pesquisas que visam proporcionar um melhor entendimento sobre essa temática, ampliando os debates sobre as ações empreendidas nessa área e os desafíos enfrentados. Palavras-Chaves: Redes ubíquas; Aprendizagem ubíqua e Educação Online.
\end{abstract}

\begin{abstract}
We live in a moment of intense ubiquity, which presents important challenges for Online Education. In the search for a better horizon, this work carried out a systematic mapping of literature with the objective of analysing the potential of Ubiquitous Connection Networks for Online Education. In our findings we observed that the discussions about the potential of Ubiquitous Connection Networks in the Context of Online Education still need to advance. However, there are good research initiatives that aim for providing a better understanding of this issue, broadening the debates about the actions undertaken in this area and the challenges faced.
\end{abstract}

Keywords: Ubiquitous networks; Ubiquitous learning; Online Education

\section{Introdução}

Desde o advento da Internet são muitas as transformações, pelas quais a sociedade vem passado e isso tem trazido um importante impacto no que tange ao acesso à informação, as relações pessoais/profissionais, as formas de se aprender e de se ensinar, para nos situarmos apenas na Educação, pois esse impacto verifica-se em todos os setores da sociedade.

Esses cenários digitais impulsionam mudanças significativas de posturas, principalmente no que tange ao papel desempenhado atualmente pela educação, afinal, são muitos os desafios que se abrem para esse campo, frente ao contexto cibercultural. É justamente possibilidade das tramas, conexões infinitas e compartilhamentos proporcionados pela cibercultura que permitem os cenários sociotécnicos em que estamos imersos. Este panorama tem sido marcado pela passagem de uma sociedade predominantemente dominada pelos átomos para uma sociedade, na qual os bits dão as cartas (Negroponte,1995). É a também chamada Era Digital.

Nessa Era (Sociedade Digital) presenciamos o fato de a mobilidade física dos sujeitos ser majorada pela mobilidade virtual das redes digitais, cujos efeitos são sentidos por meio da explosão das redes sociais no ciberespaço, quando aquelas se conectam, encontram-se. Hoje, ao simples toque dos dedos nos dispositivos móveis, a qualquer momento e em qualquer lugar, as pessoas podem acessar o ciberespaço, para lerem, conversarem, conviverem, assistirem a um vídeo, compartilharem materiais, co-criarem, entre muitas outras possibilidades que estão abertas à vida social e pessoal. São as redes de conexão ubiquas trazendo grandes mudanças para esse contexto multifacetado que estamos imersos e influenciando fortemente as relações educacionais.

Foi esse panorama que impulsionou o crescimento de cursos online no Brasil e que o motivou o presente trabalho, que tentou responder algumas questões relevantes, como por exemplo: de que forma a EOL está sendo inserida nessa paisagem tão multifacetada? Que desafios são colocados para essa modalidade de ensino? Como as redes de conexão ubiquas podem potencializar projetos no campo da EOL? Estas e outras inquietações foram os propulsores do presente trabalho. Com o propósito de compreendemos melhor essa temática e desejosos de obter respostas, mesmo que parciais, para essas e outras inquietações, tornou-se necessário realizar um mapeamento sistemático de literatura, seguido de 
uma meta-análise dos materiais elencados como mais relevantes para o estudo.

\section{Um pouco do estudo: contexto e metodologia}

No Brasil muitos dos projetos de cursos online ainda se baseiam na égide da Educação a Distância (EAD), não trazendo em seu bojo os elementos próprios da cibercultura, como a interatividade, o compartilhamento e a co-criação, servindo, basicamente, como repositório de materiais.

Santos (2014) traz em seus estudos uma forma diferente de compreender a Educação Online (EOL), pois segundo ela a EOL "não é apenas uma evolução das gerações da EAD, mas um fenômeno da cibercultura" (SANTOS, 2014, p. 56). Para a autora o que demarca o território da EAD é a separação física entre aprendizes e ensinantes, enquanto que, na EOL: os sujeitos podem até encontrar-se geograficamente dispersos, entretanto, em potência estão juntos e próximos, compartilhando informações, conhecimentos, seus dispositivos e narrativas de formação a partir da mediação tecnológica das e com as interfaces e dispositivos de comunicação síncronas e assíncronas e de conteúdos hipertextuais disponíveis no ciberespaço a partir do Ambiente Virtual de Aprendizagem (AVA) (Santos, 2014, p. 55-56).

Em consonância com o que sinaliza Santos (2014), acreditamos que vivenciamos tempos de cibercultura e na qual estamos totalmente imersos nos espaços híbridos. Dessa forma, são ressignificadas e ampliadas as noções de tempo e de espaço, permitindo que escola, família, trabalho e comunidade se imbriquem e desimbriquem ininterruptamente em um típico movimento desse contexto líquido em que estamos inseridos.

Todo esse cenário digital e o visível crescimento exponencial de cursos online, no Brasil e em várias partes do mundo, instigaram ainda mais as nossas inquietações, nos levando a realização do referido mapeamento sistemático de literatura. Para executar o que nos propomos, inicialmente buscamos trabalhos (artigos, teses e dissertações) que pudessem fornecer algumas pistas e que nos ajudassem a encontrar respostas, mesmo que provisórias, para os nossos questionamentos. O mapeamento sistemático de literatura foi realizado em três etapas: busca por descritores nas bases de dados bibliográficos, a saber: Repositório Científico de Acesso Aberto de Portugal (RCAAP), no site de periódicos da Coordenação de Aperfeiçoamento de Pessoal de Nível Superior (CAPES) e no portal do Institute of Education Sciences (ERIC), seguida da seleção dos textos que seriam trabalhados a partir da relevância e por aderência à problemática e, por fim, análise do material selecionado.

$\mathrm{Na}$ primeira etapa do mapeamento de literatura foi realizada uma busca sistematizada nas bases de dados bibliográficos assinaladas anteriormente, tomando como referência os seguintes descritores: Redes Ubíquas $e$ Educação; Redes Ubiquas e Educação Online; Redes Ubiquas e Educação a Distância. Entretanto, os resultados alcançados a partir desses descritores não foram significativos, o que nos obrigou a realizar uma nova busca usando os mesmo termos, mas em língua inglesa. Os levantamentos em voga foram realizados tendo como balizador os trabalhos publicados (artigos, dissertações e teses) a partir do ano de 2011 até o ano de 2017. Todavia, alguns trabalhos com datas anteriores às assinaladas também foram considerados tendo em vista sua relevância para a temática em voga.

$\mathrm{Na}$ primeira etapa do mapeamento foram encontrados 795 artigos que se alinhavam com os nossos objetivos, todavia, destes somente 63 foram escolhidos na segunda etapa da seleção, por fim, optamos por trabalhar com 18 artigos que foram analisados minuciosamente. Para chegarmos a esse quantitativo trabalhado, primeiramente eliminamos a duplicação de artigos, pois muitos apareciam nas três bases de dados pesquisadas; em seguida lemos os títulos e os resumos dos trabalhos, a fim de escolhermos aqueles que se vinculavam ao objetivo desse estudo e excluir os que não se relacionavam. Na etapa seguida, consolidamos a seleção do material que íamos trabalhar a partir da leitura dos resumos dos artigos com o objetivo de elencar aqueles que atendiam aos critérios estabelecidos. Finalmente, passamos ao estudo dos artigos escolhidos e para isto foram feitas fichas de leitura de cada um, a partir da contribuição de Umberto Eco (1984) e uma meta-análise deste material.

A seguir compartilhamos alguns achados que o mapeamento sistemático de literatura nos forneceu acerca da nossa temática e os desafios que são postos àqueles que, tal como nós, acreditam no potencial da EOL e das Redes de Conexão Ubiquas.

Os contributos e os desafios das Redes de Conexão Ubiqua para a Educação Online. A EOL é uma modalidade de ensino em bastante ascenção na atualidade, principalmente devido aos avanços proporcionados pelo periodo de forte digitalização que estamos vivenciando. Além disso, é uma modalidade que possui um caracter tremendamente democrático e inclusivo, pois possibilita aos sujeitos o acesso à formação e ao conhecimento, mesmo se estes estiverem longe dos grandes centros ou com uma agenda profissional/particular que os impeça de frequentar aulas presenciais. Destaca-se, ainda, que a EOL tem a tecnologia como uma condição "sine qua non" para ocorrrer, uma vez que os artefatos tecnológicos são elementos fundamentais para qualquer projeto de EOL. Quanto a este último aspecto, cabe salientar que as Tecnologias Digitais da Comunicação e Informação (TDCI) foram as grandes propulsoras para que as iniciativas no campo da EOL florescessem tanto e fornecem novos recursos para que o processo ensino/aprendizagem seja cada vez mais potencializado na EOL.

Em sintonia com o que estamos ponderando, o surgimento e utilização dos dispositivos móveis tem proporcionado importantes mudanças para a conectividade, uma vez que estes equipamentos liberaram os usuários da necessidade de estar "preso" ao um computador fixo para se conectar a internet e navegar nas diversas redes sociais, pois com esse incremento os usuários podem compartilhar, comentar, pesquisar, socializar a partir dos seus dispositivos móveis em qualquer lugar que estejam e na hora que desejarem. Eé 
isso que temos vivenciado, mais cotidianamente, nos diversos espaços que frequentamos, não sendo raras as vezes que nos transportes públicos, nos restaurantes, nos parques, entre outros lugares, nos depararmos com pessoas conectadas na web, ora para diversão, ora para tratar de assuntos profissionais ou pessoais enquanto se locomovem de um lugar a outro, experienciando plenamente todo potencial que os espaços híbridos oferecem.

A partir do uso dos dispositivos móveis surge uma nova e instigante forma de aprendizagem. É a aprendizagem ubiqua que se baseia nos imediatos e velozes acessos à Internet para a busca de informações, para as trocas instantâneas de mensagens, entre inúmeras outras possibilidades abertas pelo ciberespaço. É, portanto, a chamada aprendizagem ubíqua que pode ser categorizada como aquela que está acessível aos sujeitos, a qualquer tempo, em qualquer lugar, sempre que a curiosidade bater-lhes à porta. Nas palavras de Santaella (2013), a aprendizagem ubíqua não deve ser confundida com nenhuma outra forma de aprendizagem conhecida atualmente, não podendo ser categorizada como educação formal ou informal ou como substituta de alguma delas. Ao contrário, ela pode complementar qualitativamente a educação formal, beneficiando, assim, o processo de ensino-aprendizagem.

A aprendizagem ubíqua tem se intensificado a partir do uso dos dispositivos móveis, pois estes equipamentos permitem que a conectividade seja individualizada e personalizada. Hoje em dia, com a imersão conectiva possibilitada pela cibercultura, o conhecimento e a aprendizagem estão acessíveis a qualquer tempo e espaço. Portanto, a apenas alguns toques dos dedos, é possível ter acesso a diversas informações ou ainda solicitar ajuda às pessoas que estão geograficamente distantes, mas tão próximos virtualmente.

Embora se aproxime bastante do que chamamos de m-learning, ou seja, aprendizagem móvel, cabe destacar que esse conceito não deve ser confundido com o conceito de aprendizagem ubíqua. Segundo Traxler (2010), o m-learning se configura como uma educação mais flexível, mais personalizada, espontânea, e localizada, associada, entretanto, aos processos de educação formal. Nesse modelo, a qualquer hora e em quaisquer espaços (físicos e virtuais) os alunos podem co-criar, interagir com outras pessoas, buscar informações, socializar achados, de forma individual e/ou coletiva, transformando seus achados em uma aprendizagem significativa. Todavia, é importante considerar os contributos de Silva (2013) para essa discussão, haja vista que, segundo ela, M-learning não se refere unicamente ao acesso a conteúdos "a qualquer hora" e "em qualquer local" e em deslocamento por alunos e professores, como o acesso a materiais digitais educacionais, informações, notícias, mas envolve também interação, colaboração, aulas online, pesquisas, publicações etc., distribuídas nas redes, nos ambientes educacionais em formatos e mídias diversos. (Silva, 2013, p.130).

Ainda de acordo com a autora, os dispositivos móveis permitem que alunos e docentes estejam conectados em qualquer lugar e a qualquer momento, dimunindo e tornando, portanto, "fluidas as fronteiras de comunicação entre escola, residência e trabalho, uma interferindo, influenciando e se imbricando na outra" (Silva, 2013, p.131).

Como podemos observar, há um enorme potencial de utilização das redes de conexão ubíqua no contexto educacional, especialmente, no campo da EOL e os achados desse estudo apontam nessa direção. Chatterjee e Nath (2015), por exemplo, destacam que a utilização das redes de conexão ubíquas, juntamente com os MOOCS, seria uma forma bastante valoroza para alavancar o Ensino Superior na India, devido às dimensões territorias daquele país e ao pouco acesso da população a esse nível de ensino. Segundo os autores, Ubiquitous learning is another concept working over a similar goal of making education facilities available everywhere and to everyone. MOOCs function over an online platform which could be effectively implemented as a route to ubiquitous learning, providing education to anyone, anywhere, and on any digital device using the Internet facility. (Chatterjee e Nath, p. 608, 2015).

Em consonância com os estudos de Chatterjee e Nath (2015) entendemos que explorar o potencial da ubiquidade pode ser um fator determinante para democratizar o acesso a educação superior nos países pouco desenvolvidos ou em desenvolvimento, pois é notório o crescimento da utilização dos dispositivos móveis pela população mais jovem e nada mais apropriado que incorporar esse uso para fins educacionais. Todavia, há de se mencionar que às questões relacionadas à infraestrutura tecnológica devem ser consideradas em projetos dessa magnitude, uma vez que é fundamental dispor de uma internet com uma boa banda larga para garantir o acesso e a navegação no Ambiente Virtual de Aprendizagem (AVA) sem sustos e frustrações causados pela instabilidade dos sistemas.

Suky e Suky (2011) em seus estudos concluíram que os alunos da Educação Superior da Málásia veem como positivo a utilização da aprendizagem móvel em contextos educacionais devido principalmente "Malaysian mobile phone users" intention to positively accept the use of Mobile Learning is due to encouraging factors such as perceived mobility value and perceived usefulness of the Mobile Learning." (Suky e Suky, p.118, 2011).

Nessa mesma pesquisa e imbuídos dos achados encontrados, Suky e Suky (2011) apontam que os educadores, a partir da emergência da redes de comunicação ubíquas, precisam revisitar os seus papeis e abandonar arcaica ideia de que os docentes devem transmitir o conhecimento aos alunos, migrando para uma concepção mais atual, na qual docência é entendida como uma orientação ao percurso da aprendizagem dos estudantes. De fato, as nuances que a ubiquidade proporciona aos sujeitos é algo capaz de balançar fortemente os contextos de aprendizagem, impondo aos professores novas atitudes frente aos alunos que, dia após dia, estão cada vez mais conectados e antenados ao que ocorre no mundo.

Para corroborar com os conceitos em voga, Santos e Weber (2013) descrevem uma experiência realizada com alunos da disciplina Didática do curso de Pedagogia da 
UERJ (Universidade do Estado do Rio de Janeiro), na utilização de aprendizagem ubíqua no currículo da referida disciplina. Para realizá-la os alunos usaram os telefones celulares para tirar fotos, gravar vídeos e postar imediatamente na rede social, permitindo variadas interações, co-criações e aprendizagens multifacetadas, aspectos próprios do contexto da mobilidade na cibercultura. Os resultados encontrados indicam que proporcionar essas experiências, de pura mobilidade e ubiquidade, foram bastante significativas para os docentes em formação, pois estes puderam perceber todo o potencial do digital em rede e, quiçá, farão uso desses contributos em suas práticas pedagógicas tão logo estejam atuando.

Em outro estudo desenvolvido com jovens do Brasil e de Portugal (Silva e Souza, 2015), que participaram do Projeto Agentes Digitais, que objetivou inserir os eixos TDIC e Empreendedorismo na formação dos jovens, averiguando as mudanças e os impactos nas suas vidas pessoais e na inserção profissional. De acordo com os pesquisadores, os jovens participantes, mesmo geograficamente distantes, "criaram, compartilharam, colaboraram e cooperaram na idealização, concepção, implementação e avaliação dos respetivos projetos, entre si e em cada grupo" (Silva e Souza, 2015, p.6). Os resultados obtidos sinalizam que o uso das redes de conexão ubíqua "permitiram a presença da imagem, da fala, da escrita dos participantes e ainda a partilha de outro material de natureza hipertextual, favorecendo um processo comunicacional interativo entre todos os participantes" (Silva e Souza, 2015, p.18).

O potencial da ubiquidade para o campo educacional, especialmente para EOL, extrapola as barreiras de tempo e espaço, favorece o compartilhamentos de materias, enriquece as aprendizagens, entre tantos outros aspectos, podendo, ainda, ser um elemento que auxilia na superação do sentimento de solidão tão presente em cursos online, conforme aponta Silva e Souza (2015)

a rede de comunicação ubíqua foi a grande responsável pela dinamização desta comunidade de prática, por favorecer a integração e o sentimento de pertença entre os participantes, as trocas, as discussões temáticas e a elaboração conceitual em torno da compreensão do Coempreender (Silva e Souza, 2015, p.19).

Alinhado com essa perspectiva, a pesquisa realizada nos curso de licenciatura em Educação Infantil da Universidad El Bosque em Bogotá (Colômbia), Mesa, Pastor e Segura (2017) apontam que los ambientes u-learning fortalecen la evaluación y consolidan la investigación formativa como un proceso permanente para aprender investigación educativa por medio de la personalización, adaptación y el aprendizaje situacional, marcando diferencias significativas con respecto a los ambientes e-learning, (Mesa, Pastor e Segura, p. 17, 2017)

A exploração das redes ubiquas em projetos de EOL é algo que pode favorecer enorrmente a EOL, tanto nos aspectos relacionados a sensação de presencialidade fornecida por essas redes, como nos compartilhamentos e nas trocas que elas proporcionam aos docentes e alunos. Todavia, é importante considerar alguns aspectos para que os seus contributos sejam aproveitados em sua plenitude., para Mesa, Pastor e Segura (2017), a ubiquidade contém valiosos elementos para facilitar a aprendizagem contextual, mas os desenvovedores dos AVA devem desenhá-los visando favorecer essa incorporação, permitindo o acesso ao conteúdo apropriado, no momento adequado e no lugar indicado, garantindo assim um maior ordenamento das aprendizagens nesses espaços tão ricos em teias e conexões. Afinal, com tantas possibilidades que são abertas a partir das redes ubiquas os AVA podem (e devem) contemplá-las em suas configurações, mas isso necessita ocorrer de forma que os usuários não se sintam perdidos no emaranhado de informações disponíveis.

Os autores também ponderam que "la incorporación de los ambientes ubicuos de aprendizaje requiere una alta inversión en recursos humanos y materiales, lo que, a su vez, es una limitación y un desafío." (Mesa, Pastor e Segura, p. 17, 2017). Evidencia-se com isso que projetos dessa natureza não podem prescendir de investimentos tanto em recursos humanos, como em recursos materias. No que tange aos recursos profissionais, é mister considerar os aspectos relativos à qualificação, pois como trata-se de um cenário relativamente novo é relevante buscar estratégias formativas para os docentes que atuarão nesses projetos.

A pesquisa de Lee (2013) realizada com alunos da Educação Superior da Córeia do Sul trouxe mais um dado a ser considerado em projetos que pretendam incluir as redes de conexão ubiqua em seu bojo. Em seu estudo Lee (2013) verificou que o pequeno tamanho da tela e as plataformas dos dispositivos móveis podem ser limitadores para a aprendizagem ubiqua. Contudo, o que vemos nos diversos espaços que circulamos são pessoas conectadas e usando os seus dispositvos móveis para realizar diversas atividades cotidianas, seja para acessar a conta corrente em um banco, seja para ler revistas ou jornais, o que de certa forma contradiz, em parte, os achados de Lee (2013), reforçando a necessidade de mais estudos com essa temática.

\section{Considerações Finais}

Estamos vivendo em plena Cibercultura, onde novos artefatos culturais invadem o nosso cotidiano, permitindo que, ao toque dos dedos possamos acessar as redes sociais, ler os jornais diários, ver vídeos, compartilhar informações ao mesmo tempo que caminhamos para o trabalho, tomamos consciência que é chegada a Era da Ubiquidade.

A era da ubiquidade pode trazer siginificativos ganhos para os projeitos do campo da EOL, conforme apontado por esse estudo. Afinal, as posibilidades que são abertas a partir do seu advento são inúmeras e podem ressignificar o campo da EOL, pois os seus contributos são sentidos em varios contextos, como por exemplo, a ampliação das posibilidades de compartilhamentos que estas redes oferecem, a constituição de comunidades virtuais de aprendizagem, a superação do sentimento de solidão presente em diversos projetos de EOL e, consequentemente, uma maior sensação de pertencimento e de estar junto virtual ao se estudar em contextos virtuais e por fim, mas não mais importante, $o$ 
incremento a uma aprendizagem a qualquer tempo e a qualquer hora.

Todavia, cabe salientar que para além dos contributos, sinalizados acima, há algumas limitações na incorporação das redes ubiquas no contexto da EOL, como por exemplo, no que tange a necessidade de investimentos em ampliação da largura da banda da Internet e na disponibilização de redes móveis de qualidade para que os alunos consigam acessar e navegar nos AVA sem o inconveniente da queda de conexão. Além disso, há ainda de se considerar o tamanho das telas do dispositivos móveis e os sistemas operacionais instalados nesses aparelhos, conforme ponderou Lee (2013). Destaca-se também a necessidade formação adequada para os profissionais que atuarão em projetos de EOL que utilizem os beneficios da ubiquidade em seus desenhos didaticos.

Nesse contexto, podemos considerar que os projetos de EOL que contemplem os aspectos próprios das redes de conexão ubiquas são bastante interesantes e podem trazer valiosos contribuir para o proceso ensino/aprendizagem que ocorre na EOL.

\section{Referências}

Chatterjee, P. \& Nath, A. (2013) The Future ICT Education in India - A Pilot Study on the Vision of Ubiquitous Learning in Higher Education. Conference India 2015, Vol. 340, pp. 599-609, Springer India.

Lee, H. (2013) Conjoint Analysis for Mobile Devices for Ubiquitous Learning in Higher Education: The Korean Case. Turkish Online Journal of Educational Technology - TOJET, v12 n1 p45-51

Santaella, L. (2013) Desafios da ubiquidade para a educação. Revista Ensino Superior Unicamp.

Santos, E; \& A. Weber. (2013) Educação e cibercultura: aprendizagem ubíqua no currículo da disciplina didática. Revista Diálogo Educacional, vol. 13, núm. 38, enero-abril, (pp. 285-303). Pontifícia Universidade Católica do Paraná. Paraná, Brasil.

Santos, E. (2014). Pesquisa-formação na cibercultura. Santos Tirso: Whitebooks.

Silva, B. \& Souza, K. (2015) Redes de Comunicação ubíqua e coinvestigação: relato de uma experiência no âmbito do coempreender. In: VIII Seminário Internacional As Redes Educativas e as Tecnologias: Movimentos Sociais e Educação, RJ.

Suki, N. M. \& Suki, N. M. (2011) Users' Behavior towards Ubiquitous M-Learning. Turkish Online Journal of Distance Education, v12 n3 p118-129.

Velandia-Mesa,C., Serrano-Pastor,F.J. \& Martínez-Seg ura, M.J. (2017) Investigación formativa en ambientes ubicuos y virtuales en Educación Superior. Revista Comunicar, vol. 25, n. 51, 09-18.

\section{Agradecimentos}

This article reports research developed within the $\mathrm{PhD}$ Program Technology Enhanced Learning and Societal Challenges, funded by Fundação para a Ciência e Tecnologia, FCT I. P. - Portugal, under contracts \# PD/00173/2014 and \# PD/BI/128229/2016. 